DOSSIÊ TEMÁTICO: Educação Inclusiva e Processos de Subjetivação do/ https://doi.org/10.22481/praxisedu.v16i37.5984

\title{
O BRINCAR COMO PROCESSO DE INCLUSÃO EM OCUPAÇÕES LÚDICAS NA CIDADE DE SÃO PAULO
}

\author{
PLAYING AS AN INCLUSION PROCESS IN PLAYFUL OCCUPATIONS IN THE CITY \\ OF SÃO PAULO
}

\section{JUGAR COMO UN PROCESO DE INCLUSIÓN EN OCUPACIONES JUGUETONAS EN LA CIUDAD DE SÃO PAULO}

\author{
Bianca Rozenberg \\ Universidade Federal de Viçosa - Brasil \\ Eduardo Simonini \\ Universidade Federal de Viçosa - Brasil \\ Denilson Santos de Azevedo \\ Universidade Federal de Viçosa - Brasil
}

\begin{abstract}
Resumo: O ser humano, através das relações entre os semelhantes e com o universo a circundá-lo, criou diferentes formas de se expressar. Os jogos, os brinquedos e as brincadeiras são algumas dessas expressões e historicamente estiveram presentes na vida das pessoas, nos diferentes grupos sociais, idades e gêneros, sendo atribuídos sentidos e significados diversos consoantes à cultura lúdica. Este artigo atentou para a experiência lúdica como uma manifestação cultural, social e histórica, e diante da imprevisibilidade do brincar e das possibilidades de espaços inventivos e de criação, acompanhamos as ações, na cidade de São Paulo, do projeto "Central dos Jogos". Este tinha como proposta a difusão da cultura do brincar com o objetivo de promover vivências capazes de fortalecer vínculos e ressignificar espaços públicos a partir de Ocupações Lúdicas. Assim sendo, esta pesquisa procurou, a partir do uso de narrativas cartográficas, problematizar como a ocupação dos espaços públicos foi praticada naquela iniciativa e quais as composições de sentido e invenção foram atualizadas pelos "seres brincantes" presentes nas referidas Ocupações.
\end{abstract}

Palavras chave: Brincar; Ocupações Lúdicas; Espaços Públicos.

\begin{abstract}
The human being, through relations between their fellows and the universe surrounding them, created different ways of expressing itself. Games, toys and jokes are some of these expressions and have been present, in people's lives, historically, in different social groups, ages and genders. Different meanings and significations have being attributed to these practices in accordance with the recreational culture. So, this paper analyzed the ludic experience as a cultural, social and historical manifestation.
\end{abstract}


Faced with the unpredictability of playing and with the possibilities of inventive and creational spaces, we followed the actions of the project "Central dos Jogos" in the city of São Paulo. This was a sociocultural project that had the mission to spread the culture of playing with the objective of promoting experiences capable of strengthening ties and re-signifying the public spaces. To achieve this purpose, the project promoted the realization of Ludic Occupations. Thus, this research, through the use of cartographic narratives, followed how different people made the public spaces, using games, toys and jokes during those Ludic Occupations.

Keywords: Play; Playful Occupations; Public Spaces.

Resumen: El ser humano, a través de las relaciones entre los semejantes y el universo circundante, creó diferentes formas de expresarse. Juegos, joguetes, son algunas de estas expresiones y han estado históricamente presentes en la vida de las personas, en diferentes grupos sociales, edades y géneros, atribuyéndose diferentes significados dependiendo de la cultura lúdica. Este artículo se centró en la experiencia lúdica como manifestación cultural, social e histórica, y en vista de la imprevisibilidad del juego y las posibilidades de los espacios creativos, seguimos las acciones, en la ciudad de São Paulo, del proyecto "Central dos Jogos". La propuesta era difundir la cultura del juego con el objetivo de promover experiencias capaces de fortalecer los lazos y resignificar los espacios públicos basados en Ocupaciones Lúdicas. Por lo tanto, esta investigación buscó, mediante el uso de narrativas cartográficas, cuestionar cómo se practicaba la ocupación de espacios públicos en esa iniciativa y cuáles eran las composiciones de significado e invención actualizadas por los "seres juguetones" presentes en dichas Ocupaciones.

Palabras clave: Jugar; Ocupaciones Juguetonas; Espacios Publicos.

O ser humano, através das relações consigo, com os semelhantes e com o universo sóciopolítico a atravessá-lo e transbordá-lo, criou diferentes formas de se expressar. Os jogos, os brinquedos e as brincadeiras são algumas dessas expressões que historicamente estiveram presentes em diferentes grupos sociais e etários, sendo atribuídas às brincadeiras sentidos e significados diversos, consoantes a diferentes maneiras de produzir uma cultura lúdica.

Muitos autores têm se debruçado sobre o universo lúdico, principalmente em torno de conceitos como "jogo", "brinquedo", "brincadeira”, sendo que, nesses estudos, é possível encontrar definições, especificidades e contradições conceituais. Maturana e Verden-Zõller (2004, p.210), por exemplo, consideram:

[...] brincadeira qualquer atividade humana praticada em inocência, isto é, qualquer atividade realizada no presente e com a atenção voltada para ela própria e não para seus resultados. Ou, em outros termos, vivida sem propósitos ulteriores e sem outra intenção além de sua própria prática. Qualquer atividade humana que seja desfrutada em sua realização - na qual a atenção de quem a vive não vai além dela - é uma brincadeira. 
Ou seja, para os referidos autores, adultos e crianças brincam quando se entregam plenamente a uma atividade, sendo esse momento de entrega também um ato de liberdade e criação no/do presente, uma vez que não haveria um objetivo ou intencionalidade externa ao próprio ato de brincar. Friedman (2005), por sua vez, apresenta uma perspectiva um pouco diferenciada ao considerar o brincar como relacionado a uma "essência humana", estando numa zona de fronteira entre a realidade e a invenção de novas possibilidades. Para ele:

O brincar traz de volta a alma da nossa criança: no ato de brincar, o ser humano se mostra na sua essência, sem sabê-lo, de forma inconsciente. O brincante troca, socializa, coopera e compete, ganha, e perde. Emociona-se, grita, chora, ri, perde a paciência, fica ansioso, aliviado. Erra, acerta. Põe em jogo seu corpo inteiro: suas habilidades motoras e de movimento veem-se desafiadas. No brincar, o ser humano imita, medita, sonha, imagina. Seus desejos e seus medos transformam-se, naquele segundo, em realidade. O brincar descortina um mundo possível e imaginário para os brincantes. $\mathrm{O}$ brincar convida a ser eu mesmo. (FRIEDMANN, 2005, p.88).

Já em Luckesi, o lúdico é ele próprio uma manifestação pulsante de vida, sendo que "o lúdico é o modo de ser do homem no transcurso da vida, o mágico, o sagrado, o artístico, o científico, o filosófico, o jurídico são expressões da experiência lúdica constitutiva da vida. (...). O lúdico é a vida se construindo no seu movimento". (LUCKESI, 1994, p.51). Contudo, diferente de uma perspectiva espontaneísta ou que remeta a um discurso de essências, há aqueles que compreendem a experiência lúdica como uma manifestação cultural, social e histórica, engendrada em um complexo processo de produção coletiva. Nesta perspectiva, a identidade individual e coletiva não seria algo pré-dado por uma estrutura universal e ahistórica, mas construída por meio da identificação e da relação de indivíduos e grupos com as produções materiais e imateriais de determinadas comunidades, sendo engendradas, numa continuidade histórica, noções de pertencimento e identidade, mediadas nas práticas que constituem o que passou a ser chamado de Patrimônio Cultural. Dentre essas práticas, localizamos a questão do lúdico. A cultura lúdica é capaz de gerar o sentimento de identidade e continuidade, sendo que:

O ritual teve origem no jogo sagrado, a poesia nasceu do jogo e dele se nutriu, a música e a dança eram puro jogo. O saber e a filosofia encontraram expressão em palavras e formas derivadas das competições religiosas. As regras da guerra e as convenções da vida aristocrática eram baseadas em modelos lúdicos. Daí se conclui necessariamente que em suas fases primitivas a cultura é um jogo. Não quer isto dizer que ela nasça do jogo, como um recém-nascido se separa do corpo da mãe. Ela surge no jogo, e enquanto jogo, para nunca mais perder esse caráter. (HUIZINGA,2000, p. 193). 
Mesmo observando que a história dos jogos e do brincar teve suas mudanças no decorrer dos milênios em relação à funcionalidade dos mesmos - fossem numa dimensão sagrada ou profana - a perspectiva socializadora permaneceu como uma de suas principais características. Além disso, os brinquedos, as brincadeiras, os jogos e a cultura lúdica em si, são formas de preservar saberes populares e de se utilizar de fontes vivas de conhecimento. Portanto:

Nessa perspectiva de universalidade é que jogos e brincadeiras tradicionais devem ser pensados para que sejam percebidos como patrimônios culturais de toda a humanidade. São quase sempre criações coletivas, de domínio público, de origem dificilmente identificável e transmitidas oralmente pelos membros da sociedade. (TAVARES, 2004, p. 16).

A conservação de uma coleção, ou simplesmente de um único brinquedo, tem, junto à sua preservação, o seu valor sentimental e simbólico, quer seja pelo zelo, pela exclusividade, pela conservação do brinquedo ou pela memória - de um tempo, de uma cultura, de uma história - que ele carrega. Diversos meios podem ser utilizados para a preservação da cultura lúdica, seja através de pesquisas, investigações, catalogações e publicações acerca de brinquedos, jogos e de brincadeiras tradicionais e folclóricas; a própria exposição de acervos relacionados ao tema; espaços que promovam debates, palestras e discussões sobre a temática; as diversas mídias, sejam elas televisivas ou virtuais; no entanto, a própria socialização desta cultura, ou seja, o próprio ato de brincar, tem um grande potencial de preservação, continuidade e reinvenção desta memória lúdica. Assim sendo, pode-se compreender o brinquedo como um patrimônio vivo, uma vez que sua conservação está intimamente relacionada à vitalidade do uso a que ele é submetido, reavivado e mesmo reinventado no próprio ato do brincar... Ou seja, "quando uma criança interioriza uma brincadeira, ela está incorporando e tendo a oportunidade de reformular uma série de conhecimentos e parâmetros que compõem o patrimônio cultural da sociedade a que pertence" (TAVARES, 2004, p. 17).

Desta forma, assumimos neste artigo o jogo, o brinquedo e o universo lúdico como um patrimônio cultural imaterial da humanidade, por nos remeter a questões que ocupam o espaço contemporâneo e por apresentarem contínuas mutações e efeitos sociais diários. Isso porque os brinquedos e os jogos não são estáticos, mas intensidades vivas, presentes e atualizadas pelos seres brincantes, uma vez que “(...) assim caminha a cultura lúdica, que não é apenas um legado cultural, é também construção, revigorada na ação de cada brincante” (KLYSIS, 2010, p.90).

Se entendermos a cultura lúdica enquanto um movimento contínuo de construção do indivíduo dentro de um determinado meio, perceberemos que influências como a inserção social, as relações com a cidade em que se vive e as experiências passadas a produzirem efeitos 
identitários, contribuem nesta construção dos sujeitos. O que faz Debortoli (2004) considerar que o brincar se constitui na inserção cultural, expressando-se como linguagem e como processo de elaboração de significados e sentidos coletivos, contextualizados e enraizados no universo social que o legitima. $\mathrm{O}$ que, por sua vez, pressupõe que a brincadeira seja tanto um processo de adequação às regras de um grupo social, quanto também uma dinâmica a oportunizar a gestação de sentidos inéditos nas relações. Ou seja, brincar, enquanto processo vivo, é uma dinâmica que pode ser produtora de invenções. Nesse sentido, segundo Brougère:

[...] a brincadeira dá testemunho da abertura e da invenção do possível, do qual ela é o espaço potencial do surgimento. A brincadeira que pode ser, às vezes, uma escola de conformismo social, de adequação às situações propostas, pode, do mesmo modo, tornar-se um espaço de invenção, de curiosidade e de experiências diversificadas, por menos que a sociedade ofereça às crianças os meios para isso. Acontece que essa abertura marca um dos aspectos essenciais das sociedades modernas, caracterizadas pela indeterminação do futuro de cada indivíduo. A eventualidade da brincadeira corresponde, intimamente, à imprevisibilidade de um futuro aberto. (BROUGÈRE,1995, p.107).

Desta forma, o brincar se abre para uma experiência mais coletiva, onde as maneiras de se fazer brincante se engendram a modos políticos e sociais de se compor uma vida. E nos aproximando um pouco mais desse aspecto inventivo do brincar, no presente trabalho propomos o conceito de "processo brincante" para nos referirmos não a um sujeito específico a realizar a atividade de brincar, mas à própria dinâmica de conexões, de encontros e de movimentos que compõem o brincar tanto em sua ludicidade quanto em sua transversalidade com o urbanismo, as políticas públicas, a infância, a educação, a memória, as lógicas econômicas e a outras aberturas sensíveis de universo de sentido. Assim, por "processo brincante" não temos uma entidade individualizada ou corporificada, mas sim o próprio movimento plural de criação de composições de sentido na relação entre os sujeitos, brinquedos, espaços e os mundos que eles ativam nessa trama. $\mathrm{O}$ "processo brincante" seria, pois, a própria abertura à experiência, a qual “(...) não é o caminho até um objetivo previsto, até uma meta que se conhece de antemão, mas é uma abertura para o desconhecido, para o que não se pode antecipar nem 'pré-ver' nem 'prédizer'”. (LARROSA, 2002, p.28). Caminho este que supõe não apenas a abertura a diferentes sensibilidades e a outros possíveis - ainda que sutis - de realidade, mas também à curiosidade e à criatividade (em seus aspectos de novidade e risco). O "processo brincante" seria uma abertura à experiência de núpcias entre diferentes mundos e expressões, não se limitando a um jogo ou a um brinquedo. 
São esses processos brincantes a ultrapassarem a interioridade de indivíduos espacial e temporalmente localizados que nos propomos a seguir quando adentramos, durante o ano de 2015, no projeto Central dos $\operatorname{Jogos}^{1}$ e nas consequentes Ocupações Lúdicas ${ }^{2}$ realizadas pelo mesmo. Estas últimas se desdobram em instalações em que o espaçotempo se desfaz para a imersão completa no brincar. É quando as pessoas se perdem na brincadeira e se encontram com outros, compartilhando sensações por meio de inúmeros jogos e brinquedos populares do mundo todo.

\section{O brincar ocupa a cidade de São Paulo}

A Central dos Jogos é um projeto sociocultural realizado na cidade de São Paulo/SP e cujo objetivo incialmente consistiu em difundir a cultura do brincar, apostando nesta como sendo uma vivência com potencial capacidade de fortalecer vínculos sociais e ressignificar espaços públicos. O referido projeto nasceu em 2015 fruto da iniciativa de seis educadores, graduados em Pedagogia pela Faculdade de Educação da Universidade de São Paulo (FEUSP). Paulistanos, atuantes em movimentos e projetos sociais, que visualizaram, diante do incômodo com a vida urbana de uma grande metrópole, a potência social dos jogos, brinquedos e brincadeiras. Assim, através de "Ocupações Lúdicas", a Central dos Jogos se propôs a criar "ambientes brincantes" e abertos que promovessem vivências significativas de troca, experimentação e encontros, favorecendo o ressignificar das relações com os outros e com os espaços públicos da cidade.

Dessa forma, usando de uma Kombi carregada de jogos, brinquedos e brincadeiras tradicionais e populares do Brasil e de outros países, a Central dos Jogos desenvolveu suas atividades em diversas regiões da cidade de São Paulo, respeitando as características e necessidades do local visitado e das pessoas ali presentes.

O projeto piloto teve como objetivo atuar em duas localidades de São Paulo situadas na zona Oeste da cidade, sendo estas no bairro Jaguaré (mais especificamente em uma comunidade chamada Mutirão) e no bairro Butantã, na comunidade São Remo. Foram realizadas articulações com as lideranças e/ou instituições comunitárias atuantes nestes locais, e, a partir

\footnotetext{
${ }^{1}$ Em seu início, o projeto foi denominado de "Kombi dos Jogos"; contudo, durante seu desenvolvimento (e até o presente momento, uma vez que este é ainda um projeto ativo) ele passou a ser chamado de "Central dos Jogos". Optamos, então, neste trabalho, por apresentá-lo em sua denominação atual.

2 Por "Ocupação Lúdica" entendemos as intervenções urbanas realizadas pelo projeto, uma vez que as mesmas ocorriam em praças públicas, quadras de esporte, centros comunitários, etc.
} 
das mesmas, se processaram quatro Ocupações Lúdicas em cada bairro entre os meses de abril e setembro de 2015.

Durante os referidos meses, através de contatos e de pessoas que se interessaram pelo projeto ou estiveram nas ocupações, surgiram outros convites para a atuação brincante daqueles que dirigiam a Kombi. Desta forma, os participantes do projeto tiveram a oportunidade de realizar ações em outras localidades de São Paulo, por vezes em parceria com outras instituições ou eventos. Nesse sentido, as ocupações realizadas durante o ano de 2015 se deram, através do projeto piloto, no Jaguaré (11 e 12/04; 31/05 e 27/06), na São Remo (20/06; 28/06; 16/08; 30/08) e, a partir de outros convites, houve participação da Central dos Jogos na "Semana Mundial do Brincar", realizada na Praça Coronel Fernando Prestes no Bom Retiro, em parceria com a Casa do Povo e com a Aliança pela Infância (24/05); no evento "Juntos pelo Brincar", no Largo da Batata, em comemoração aos 25 anos do Estatuto da Criança e do Adolescente (05/07); no Festival de Iniciativas Colaborativas (Cocidade) no Boulevard São João (26/09); e no Festival CURAU (Cultura Regionais e Artes Urbanas), em Piracicaba, no interior do Estado de São Paulo (22/08). Para este trabalho, foram utilizados exemplos de encontros relacionais de Ocupações Lúdicas realizadas no Jaguaré, São Remo e Boulevard São João. Assim, as Ocupações Lúdicas foram sustentadas na perspectiva de que os jogos e brinquedos são um patrimônio histórico cultural da humanidade, mas, antes de tudo, um patrimônio vivo e, por isso, deveriam estar prioritariamente em locais públicos, promovendo o encontro entre as pessoas nestes espaços.

Assim, quando, no segundo semestre de 2015, seguimos os "processos brincantes" ativados no encontro entre os jogos e a cidade, temos que nossa investigação não se restringiu apenas aos jogos da Kombi, mas ao próprio processo de Ocupação Lúdica, que dizia respeito também a diferentes modos de morar e transitar na cidade de São Paulo. Segundo Rolnik (1994, p.19):

[...] construir e morar em cidades implica necessariamente viver de forma coletiva. Na cidade nunca se está só, ainda que o próximo ser humano esteja para além da parede de um apartamento vizinho ou num veículo no trânsito. O homem só no apartamento ou o indivíduo dentro do automóvel é um fragmento de um conjunto, parte de um coletivo.

E na cidade de São Paulo, como igualmente em outros centros urbanos, os modos de habitar podem influenciar a organização dos espaços públicos e igualmente as maneiras de usar a cidade. Quem vive São Paulo pela primeira vez dificilmente conseguirá apreender de uma só vez a dimensão complexa daquele "caos organizado"; pois São Paulo parece seguir as 
indicações de Calvino (1990, p. 15) quando este narra que "a cidade de quem passa sem entrar é uma; é outra para quem é aprisionado e não sai mais dali; uma é a cidade à qual se chega pela primeira vez..." (CALVINO, 1990, p.15); e acrescentamos, ainda, que é outra para quem sempre ali viveu, sai para viver outras cidades e retorna.

São Paulo, a maior e mais populosa área urbana do país, é uma cidade marcada por contrastes e profundas desigualdades, resultantes, em grande medida, do crescimento desenfreado e das políticas públicas das últimas décadas que definiram suas estruturas urbanas e sociais. $\mathrm{O}$ alto índice de violência e a forte presença da criminalidade fizeram com que fossem construídos cada vez mais cercas e muros na cidade. Por conseguinte, os espaços públicos, como ruas e praças, deixaram de ser pontos de encontro e convivência pacífica e compartilhada, tornando-se, no imaginário urbano contemporâneo, espaços de ninguém. O esvaziamento desses locais potencialmente contribuiu com um empobrecimento das relações sociais e uma consequente perda de senso de comunidade, essencial para a mobilização dos moradores em coletivos de luta por direitos e por transformação social. Como salienta Rolnik a respeito de São Paulo:

Cidade de mil povos, capital financeira, cidade conectada no mundo virtual e real das trocas, potência econômica do país, berço de movimentos sociais e lideranças políticas. No entanto, é uma cidade partida, cravada por muros visíveis e invisíveis que a esgarçam em guetos e fortalezas, sitiando-a e transformando seus espaços públicos em praças de guerra. (ROLNIK, 2001, p.10).

Desta forma, para a autora o uso do espaço público cada vez mais se torna problemático, pois campo de circulação sem cultivo, terra em disputa, território de ninguém. Augé (1994) denomina esses espaços de circulação - como praças, estações de trem, rodoviárias, aeroportos, parques de lazer, cadeias de hotéis, etc - como sendo "não-lugares", uma vez que neles não se cria necessariamente uma experiência de pertença identitária, mas uma dinâmica de passagem e de transitoriedade. Esses "não-lugares" podem inclusive se configurarem enquanto representação coletiva, como um espaço de ninguém, como lugar perigoso e/ou como refúgio de sobrevivência para trabalhar/morar para aqueles econômica e socialmente menos favorecidos: pois igualmente "sem lugar", deslocados das territorialidades reconhecidas e valorizadas socialmente.

Desta forma, na busca por se estabelecer identidades estáveis contra o que é fluido, em muitos centros urbanos pode ser observada uma crescente construção de condomínios fechados. Nestes, muros e grades são erigidos por todos os lados a protegerem aqueles espaços privados 
das desordens dos espaços públicos, principalmente quando estes últimos são assumidos como não-lugares ou "praças de guerra". Diante disto, a proposta da Central dos Jogos de ofertar atividades de lazer nos espaços urbanos públicos, esses "não-lugares" de passagem a se transformar em terra-de-ninguém, ambiciona o fomento da potência de criar outras maneiras de transitar-vivenciar tais espaços, funcionando o lazer como um instrumento anti-exclusão na cidade (ROLNIK, 2000). Contudo este lazer, mais do que apenas uma atividade recreativa, é igualmente assumida como atividade transformadora, pois também entendida em uma dimensão política, uma vez que o lazer pode vir a ter:

[...] um caráter 'revolucionário', pois é no tempo de lazer, onde se procura a vivência de alguma coisa pela escolha e satisfação, o encontro com pessoas ou com o 'novo' e o 'diferente', que se encontram possibilidades de questionamento dos valores da estrutura social e, inclusive, das relações entre sociedade e espaço. As diferenças criam 'espaço' para o conflito, o que pode provocar dúvidas e reflexões. (PELLEGRIN, 1996, p.33).

É nesse sentido "revolucionário" que o projeto Central dos Jogos pensou o movimento das Ocupações Lúdicas, sendo que o termo "ocupação" ganhou relevância de intervenção social nos usos de espaços públicos. Acompanhamos, pois, algumas dessas ocupações na tentativa de realizar uma cartografia dos "processos brincantes", sendo que tal proposta cartográfica teve inspiração nos trabalhos de Deleuze e Guattari (1995), quando estes se valeram do conceito de rizoma ${ }^{3}$ para propor um diferente modo de entender a realidade: realidade esta compreendida enquanto trama, agenciamentos, conexões e (des)encontros a formarem um tecido rizomático. Segundo Rolnik (1989), paisagens sociais podem ser cartografáveis, sendo também entendidas numa perspectiva rizomática, sendo que cartografar uma trama social consiste em seguir suas conexões, acompanhando os processos que desta emergem. Sendo assim, "o objetivo da cartografia é justamente desenhar a rede de forças à qual o objeto ou fenômeno em questão se encontra conectado, dando conta de suas modulações e de seu movimento permanente" (BARROS; KASTRUP, 2010, p.57).

Ao seguir, pois, os usos que diferentes sujeitos fizeram dos jogos, brinquedos e brincadeiras durante as Ocupações Lúdicas, tivemos a oportunidade de problematizar tais dinâmicas e as suas possiblidades na (re)invenção dos espaços públicos e relacionais. Dessa

\footnotetext{
${ }^{3} \mathrm{O}$ rizoma é biologicamente definido como um caule modificado em forma de raiz, podendo formar bulbos e tubérculos. Estes são ricos em reservas energéticas para as plantas e apresentam crescimento horizontal, formando teias vegetais que ligam uma planta a outra. Assim, não necessariamente imergindo em profundezas, os rizomas formam redes conectivas como ocorre com as gramíneas que, mesmo possuindo raízes fasciculadas, estão tecidas em rizomas.
} 
forma, parafraseando Barros e Kastrup (2010, p.73), "podemos dizer que assim a pesquisa se faz em movimento, no acompanhamento de processos, que nos tocam, nos transformam e produzem mundos". Nesse sentido, as narrativas cartográficas desenvolvidas neste trabalho foram compostas e tramadas junto a nossas sensações e experiências com os "processos brincantes”, ou seja, junto às pessoas, aos brinquedos, como também junto às configurações sociais e econômicas de diferentes bairros visitados e às singularidades de praças da cidade que eram, em suas diferentes arquiteturas, também atores a potencializarem ou não os encontros lúdicos.

Deste modo, no presente trabalho fomos pesquisadores, observadores, conversadores abertos às possibilidades de envolvimento, no estarmos atentos aos afetos e emoções a praticarem mundos no convívio durante as ocupações. Foram narrativas construídas durante o processo das Ocupações Lúdicas, escritas com as intensidades que nos atravessavam no momento em que a cidade, o brincar, o acaso, o espanto..., tudo nos mobilizava. Narrativas, pois, tramadas no que também nos afetava tanto como pesquisadores quanto igualmente como agentes brincantes na cidade. E, no desenvolvimento das narrativas que se seguirão, seguimos as orientações de Spink (2008) a respeito do fazer pesquisa nos cotidianos, quando considera que "ao contrário dos métodos planejados em que se delineia a priori um roteiro de perguntas sobre um tema previamente acordado e operacionalmente definido, ser um pesquisador no cotidiano se caracteriza frequentemente por conversas espontâneas em encontros situados" (SPINK, 2008, p.72).

Portanto, ao utilizar de narrativas para traçar uma cartografia de encontros no processo das Ocupações, inserimo-nos como pesquisadores no/do/com os cotidianos brincantes que emergiam dos encontros entre os jogos e os microlugares da cidade de São Paulo. Nesse sentido “o cotidiano se compõe de milhares de micro-lugares; não é um contexto eventual ou um ambiente visto como pano de fundo. Os micro lugares, tal como os lugares, somos nós; somos nós que os construímos e continuamos fazendo numa tarefa coletiva permanente e sem fim" (SPINK, 2008, p. 71).

Apresentamos, então, alguns desses movimentos nos microlugares que construímos e igualmente cartografamos nos processos do acompanhar as intervenções da Central dos Jogos e seus diferentes efeitos inclusivos nos encontros ativados. 


\title{
Narrativas Cartográficas
}

Figura 1 - Ocupação Lúdica - Boulevard São João

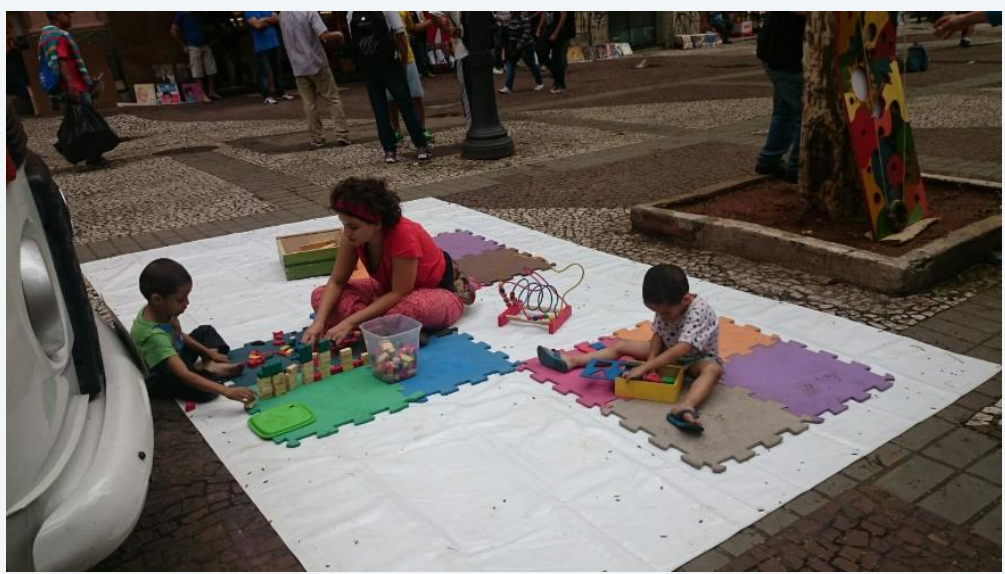

Fonte: arquivo dos pesquisadores

\begin{abstract}
Brincar com a cidade é poder revelar e descobrir esses segredos. Brincavam ali mesmo no calçadão, em uma rua onde só pedestres podem circular, um menino por volta de quatro anos e uma das educadoras/mediadoras daquela Ocupação Lúdica. A brincadeira era construir. Com pequenas e variadas pecinhas de madeira surgia pouco a pouco um castelo. Umas das peças sugeria uma ponte. E entre as pontes que atravessavam aquele diálogo a conectar dois mundos entres os brincantes desta cidade, compartilhavam descobertas. "Posso te contar um segredo?" Pergunta a mediadora, olhando nos olhos curiosos da criança sentada ao seu lado que, respondendo apenas com o olhar, paralisou-se para escutar atentamente: "Aqui, embaixo dessa rua, passa um rio". E o menino saiu correndo para contar a descoberta aos irmãos mais velhos (Narrativas Cartográficas, Ocupação Lúdica - Boulevard São João, SP).
\end{abstract}

Soler (2006, p. 15) sustentou que "você pode descobrir mais sobre uma pessoa em uma hora de brincadeira do que em um ano em conversa”. Será mais fácil também conhecer os segredos de uma cidade durante uma brincadeira? Que outros fluxos, além de rios subterrâneos, poderiam ser apresentados aos brincantes no ato de igualmente produzir diferentes encantamentos no trânsito urbano? Durante as Ocupações Lúdicas diversas vezes, como cartógrafos, fomos afetados por cenas que indicavam que outros fluxos e rios de sentido vitalizavam diferentes modos de viver, ainda que estes ganhassem intensidade experiencial em espaços insuspeitos. Eram cenas que deixavam visíveis outras cidades que não se explicitavam na rotina de um cotidiano aparentemente imutável, lançando-nos, assim, em experiências indicativas da possibilidade de abertura a diferentes universos de expressão a partir do brincar. A cena abaixo retrata um desses momentos. 
Figura 2 - Ocupação Lúdica - São Remo

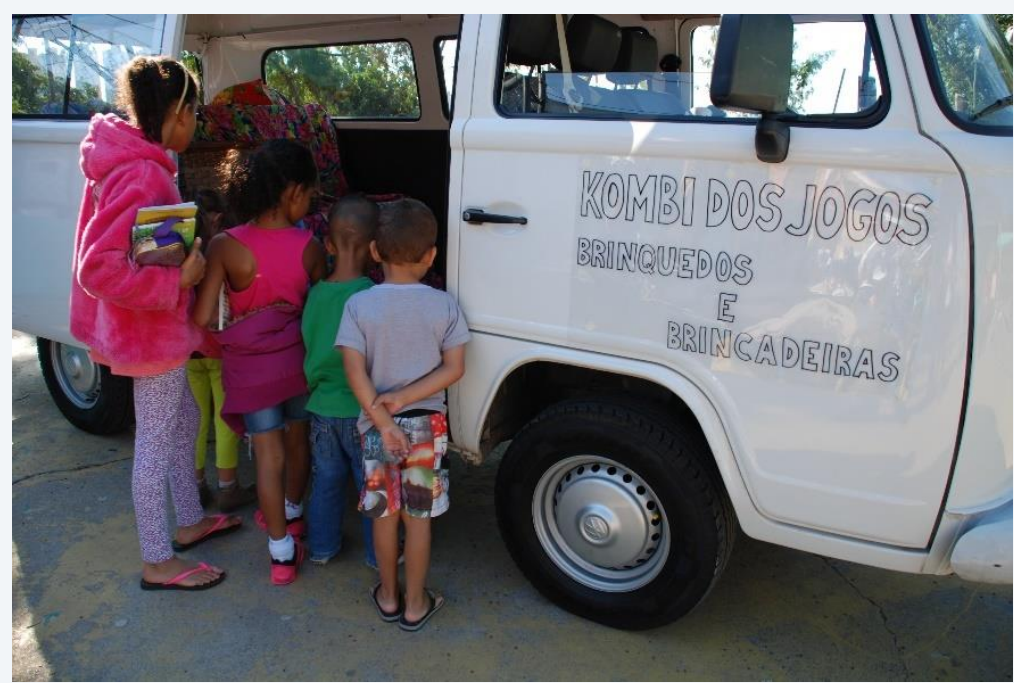

Fonte: arquivo dos pesquisadores

A chegada de uma Kombi recheada de jogos e brinquedos sem dúvida atrai as crianças com seus olhares curiosos para saber o que sairá de dentro quando a porta de correr abrir. A abertura das crianças sempre esteve em evidência. Abertas para descobrir, abertas para as tentativas, abertas para o novo ou para o velho brinquedo já conhecido; abertas para jogar com alguém que nunca tinham visto, abertas para experimentar. Os adultos, muitas vezes, observam de longe, fechados, talvez com as chaves escondidas em algum lado. Aos poucos, alguns parecem procurar suas chaves. Alguns se abrem através do convite de uma criança ou de um educador. Outros se aproximam lentamente - como quem vai buscando a chave para se abrir, mas ainda não a encontra e seguem admirando as crianças, os jogos, os brinquedos de outrora que lhes parecem familiar ou ainda desconhecidos, mas que despertam a curiosidade. Com ar de desconfiança começam a encaixar a chave que abrirá seus cadeados. E, quando a porta está correndo para fechar a Kombi, surge a voz de uma mulher de meia idade que, desta vez, fez questão de se aproximar: "Muito legal o projeto, porque a gente se sente de novo na infância. Na verdade a gente nunca perde essa infância né? Ela está aqui guardada na gente, parece que a gente recupera ela porque nunca deixamos de ser criança" (Narrativas Cartográficas, Ocupação Lúdica -São Remo, SP).

A fala daquela senhora, destacada no texto acima, nos fez sentir-perceber que a condição de infância, enquanto abertura à experiência, não se restringe à idade cronológica, mas à disposição de se permeabilizar aos acontecimentos vividos. Pois a experiência não é necessariamente aquilo que acontece, mas o que nos acontece e como damos sentido, uma vez que "no saber da experiência não se trata da verdade do que são as coisas, mas do sentido ou do sem-sentido do que nos acontece (LARROSA, 2002, p.27). Quando pois, fazemos a relação entre experiência e infância, consideramos que esta última se compromete com um movimento de abertura experimental; contudo, tal infância-experiência não se limita à restrição cronológica de um período de desenvolvimento. 
Nesse sentido, na construção deste trabalho defendemos que há uma infância experimental que também atravessa o mundo adulto; uma infância que persiste-resiste e (re)existe, pois "não há como abandonar a infância, não há ser humano inteiramente adulto. A humanidade tem um soma infantil que não lhe abandona e que ela não pode abandonar. Rememorar esse soma infantil é, segundo Agamben, o nome e a tarefa do pensamento. (KOHAN, 2003, p.245). Esta citação nos remete àquela usual pergunta feita pelos adultos às crianças: “O que você vai ser quando crescer?” E já nos soa sem sentido, pois parte da premissa de que a criança será algo ou alguém apenas quando for adulto, existindo enquanto sujeito de fato ao abandonar a condição de infância. E, no entanto, a pergunta que talvez melhor caiba aqui seja destinada àqueles se confrontam contra a dimensão dessa infância-experimental: “O que você deixou de ser quando cresceu?".

Assim, durante as Ocupações Lúdicas, tornou-se comum escutar de alguns adultos a frase "Isto aqui faz tempo que não jogo, que eu nem sei se eu lembro mais". Tal frase se repetia, a exemplo de um mantra, quando muitos adultos se viam convidados - fosse pela equipe de educadores da Central dos Jogos ou pelas próprias crianças (que chamavam seus pais, avós ou familiares/responsáveis) - a brincar. Nesse sentido, em uma das ocupações fomos afetados pela seguinte cena:

Uma criança, por volta de sete ou oito anos, queria aprender a jogar pião e pediu auxílio aos educadores. Foi quando o pai daquela criança se aproximou e, percebendo as tentativas frustradas do filho, começou timidamente a enrolar o barbante no pião, mas avisando: "Isso aqui faz tempo que não jogo, que eu nem sei se eu lembro mais". Contudo, o que observamos a seguir foram muitos rodopios! O pião girou! Girava no chão, girava na mão, rodopiava em manobras que começaram a surgir! Se aquele pai ainda se lembrava de como brincar ou se (re)aprendeu ali, não sabemos, mas o filho, os educadores e a mãe - que até então observava de longe e naquele momento se aproximou ficaram impressionados com tamanha habilidade paterna. E a criança, antes de ir embora, pedia: "deixa eu levar o pião pra casa, deixa?". Resta saber: seria para quem brincar? (Narrativas Cartográficas, Ocupação Lúdica - Jaguaré, $\mathrm{SP})$

O aviso dado pelo pai antes de brincar com o pião nos fez questionar sobre as possibilidades desta aparente lembrança do processo de rodopiar este brinquedo. Seria possível ele ter esquecido como se joga e naquele momento ter repentinamente se (re)lembrado? Esta lembrança poderia estar "presa", "chaveada" no seu passado e vir à tona naquele momento, no presente? Ou melhor, aquele pai conseguiu jogar o pião de modo similar a como o lançava quando criança? 
No decorrer da história do pensamento ocidental, muitos se debruçaram sobre temas como o tempo e a memória. Segundo Bergson (1972), o tempo é uma sucessão, uma continuidade, uma duração. De acordo com Coelho (2004, p.240):

\begin{abstract}
Bergson, algumas vezes, define o tempo como uma "continuidade indivisa de mudança heterogênea". A sucessão temporal é uma mudança ou fluxo contínuo incessante, uma transformação ininterrupta. (...) Segundo Bergson, trata-se de um escoamento ou de uma passagem, mas de um escoamento e de uma passagem que se bastam por si mesmos, o escoamento não implicando uma coisa que corre e a passagem não pressupondo estados pelos quais se passa: a coisa e o estado são apenas instantâneos artificialmente tomados sobre a transição; e esta transição, a única naturalmente experimentada é a própria duração. (COELHO, 2004, p.240).
\end{abstract}

Como duração, em Bergson o passado não é um lugar que "já se foi”, mas uma experiência viva a ser atualizada e igualmente ressignificada no presente. Sendo assim, o brincar com o pião naquele momento pode ser posto como potencializador desta memória continuamente ressignificada, pois ativa e criativa. Naqueles instantes, naquela sucessão de continuidades, entre um rodopio e outro de um pião lançado por uma pai que se agenciava a um devir experimental de infância, reatualizou-se um "processo brincante" que não estava enterrado em um passado, mas reinventado naquele vivo agora cotidiano. Foi um processo que agenciou infância-pião-memória-praça pública-brincadeira-família, no qual um pai girou um pião pela primeira vez com seu filho. O passado veio à tona não como uma dado mecânico, mas para ser (re)inventado no presente e, assim, talvez possibilitar outros futuros, outros rodopios relacionais. As experiências vividas ali, que durante uma brincadeira em que pai e filho faziam giros e manobras com seus mundos, deixaram-nos com a forte sensação de que memória é presente, memória é alma: memória-alma ativada no brincar.

Dessa forma, os "processos brincantes" ativados pelas Ocupações Lúdicas envolveram pessoas de diferentes idades e gerações que, ainda por momento fugazes, puderam produzir outras ritmações de mundo, criando laços e vínculos afetivos - com outros sujeitos e com o próprio espaço público - no movimento de "apenas" brincar. Contudo, esse "apenas" não é uma subtração da experiência, mas uma ampliação da mesma, pois focados na produção de uma outra realidade no convívio, ampliavam por alguns momentos seus mundos, antes de retomarem à velocidade rotineira de seus passos pela cidade de concreto.

Assim, o brincar, funcionando como uma ruptura, como uma suspensão do ritmo no criar de outras melodias existenciais, era revolucionário por inventar um outro modo de existir 
no tempo e no espaço público. Tais reflexões nos fazem recordar uma última cena da Ocupação

Lúdica no Boulevard São João, a ser apresentada a título de conclusão:

Duas meninas segurando muitos balões nas mãos (balões estes que elas tinham que vender), acercam-se dos jogos e dos brinquedos que estavam espalhados pela rua. Estavam meio tímidas ou sem saber como deveriam fazer para participar da Ocupação e apenas observavam outras pessoas brincando e jogando. Passeavam com seus balões por entre as mesas e a Kombi estacionada. Aos poucos, começaram a tocar nos jogos, como que indicando que gostariam de participar, e os educadores da Central do Jogos anunciaram que poderiam brincar com tudo que estava por ali. E elas? Olharam para os balões e voltaram a olhar para os jogos... A mais nova logo pediu a um dos educadores: "Segura pra mim?". Enquanto a mais velha rapidamente começou a bambolear com tamanha destreza, segurando os balões e rodopiando o bambolê. Após algum tempo - e depois de diferentes educadores segurarem os balões para que elas pudessem brincar - nos pareceu, ao vê-las conversando, que elas gostariam de ficar por ali e talvez passar a tarde brincando na rua de uma cidade que também era delas. Contudo, estavam em conflito com este desejo, pois deveriam seguir vendendo os balões para outras crianças brincarem: o qual era o real motivo de circularem por aquele espaço. E chegaram à conclusão de que naquele local ninguém os compraria, pois as crianças que por ali passassem já teriam outras oportunidades para brincar. E, assim, seguiram seu rumo para continuar vendendo seus balões (Narrativas Cartográficas, Ocupação Lúdica - Boulevard São João, SP).

Figura 3 - Boulevard São João

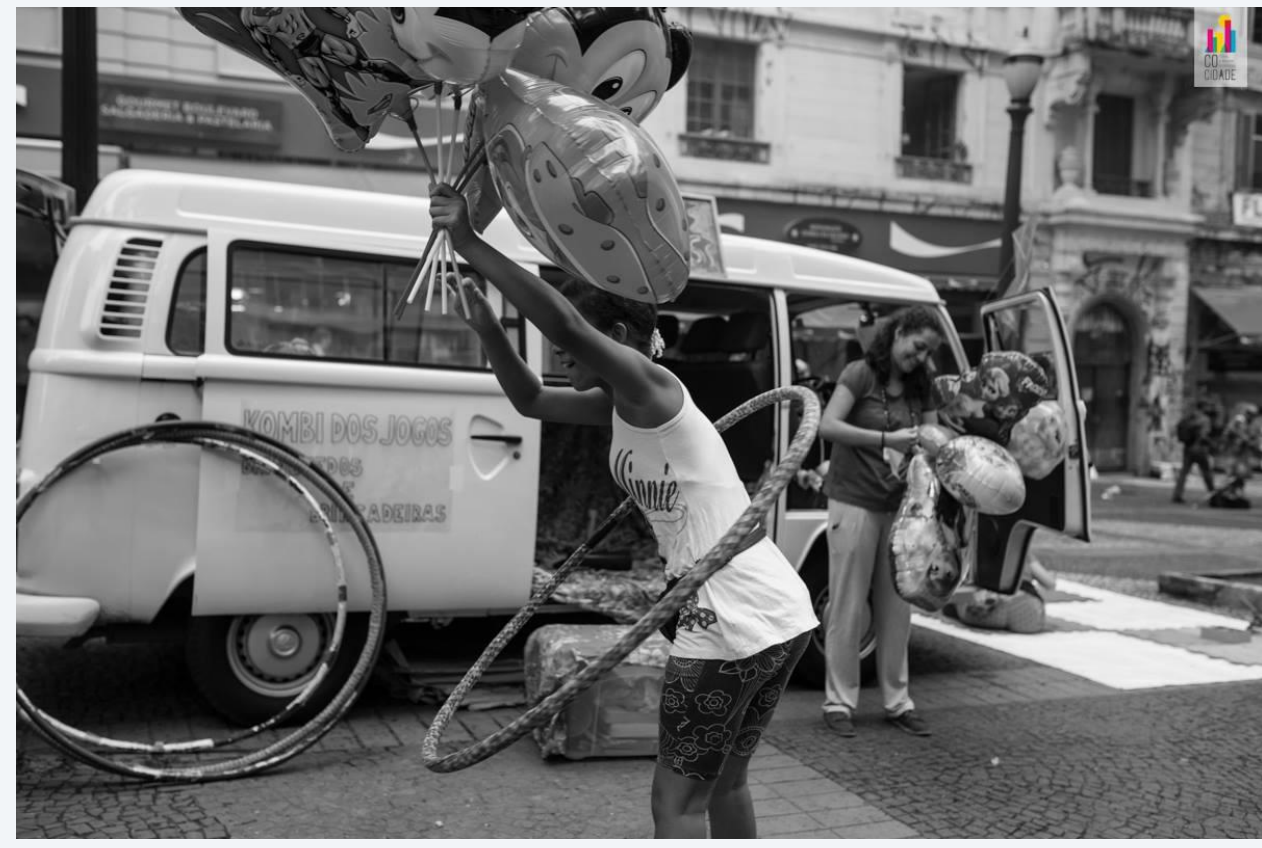

Fonte: arquivo dos autores

A cena acima narrada ocorreu durante o "Festival Cocidade", encontro este que reuniu diversas iniciativas cooperativas e colaborativas a oferecer diferentes oficinas e atividades 
gratuitas no espaço público. E como apresentado, as crianças que vendiam balões vivenciaram ali a tensão entre experienciar brincadeiras e ter que vender um brinquedo (do qual não podiam usufruir) a outros. Eram crianças furtadas do movimento de brincar, uma vez que tendiam a responder a urgências econômicas e de sobrevivência. De maneira diferente, mas relacionado à proibição do brincar em nome das urgências financeiras, podemos igualmente problematizar como as pessoas que vivem imersas nas acelerações contemporâneas tendem a ignorar "processos brincantes” para poderem fazer rodar máquinas financeiras, máquinas de repetição ritual e muitas vezes máquinas de tristeza e de vazia seriedade.

Pensar em uma cidade para todos inclui a produção de lugares que oportunizem convergências entre espaços de moradia, trabalho e lazer. Lugares que acolham tanto prédios comerciais, quanto também o movimento brincante de produzir vida em parques, praças ou mesmo ruas. Lugares que propiciem a oportunidade de desfrutar a cidade de diferentes modos - mesmo que seja no girar de um bambolê ou no rodopiar de um pião - ativando relações desejantes que, de certa forma, têm o poder de igualmente modelar a cidade. Desta forma, como insiste Calvino (1990, p. 36,37), talvez não faça sentido dividir as cidades em categorias de feliz ou infeliz, “(...) mas em outras duas: aquelas que continuam ao longo dos anos e das mutações a dar forma aos desejos e aquelas em que os desejos conseguem cancelar a cidade ou são por esta cancelados". Acreditamos que as Ocupações Lúdicas, a tramarem com experiências de memória, de tempo e de espaço, trouxeram consigo a potência desejante de, cancelando ritmos padronizados de alguns ocupantes da cidade, promover processos inclusivos que alteravam os sentidos instituídos de habitar os espaços urbanos. Dentro desta conjuntura, entendemos que o projeto Central dos Jogos é um instrumento possível que oportuniza tramas rizomáticas a compor o tempo e o espaço em outras experiências de realidade nos "processos brincantes": tanto de produção de outros sentidos para o "si mesmo", quanto também de novas sensibilizações a usos dos espaços urbanos ocupados.

\section{REFERÊNCIAS}

AUGÉ, Marc. Não-lugares: Introdução a uma antropologia da supermodernidade. Campinas, SP: Papirus, 1994.

BARROS, Laura Pozzana de; KASTRUP, Virgínia. Cartografar é acompanhar processos. In: PASSOS, Eduardo; KASTRUP, Virgínia; ESCÓSSIA, Liliana da (org.) Pistas do método da cartografia. Porto Alegre: Sulina, 2010. 
BERGSON, Henri. Mélanges. Paris: PUF, 1972.

COELHO, Jonas. Ser do tempo em Bergson, Interface - Comunicação, Saúde, Educação. v.8, n.15, p.233-46, mar/ago 2004. Disponível em: http://www.scielo.br/pdf/icse/v8n15/a04v8n15

BROUGÈRE, Gilles. Brinquedo e cultura. São Paulo, SP: Cortez, 1995.

CALVINO, Ítalo. As cidades invisíveis. São Paulo, SP: Companhia das Letras, 1990.

DEBORTOLI, José Alfredo Oliveira. Brincadeira. In GOMES, Christianne Luce (Org.)

Dicionário crítico do lazer. Belo Horizonte: Autêntica, 2004. p. 19-24.

DELEUZE Gilles \& GUATTARI, Félix. Mil Platôs: capitalismo e esquizofrenia. São Paulo: Ed. 34, vol. 1, 1995.

FRIEDMANN, Adriana. O universo simbólico da criança: olhares sensíveis para a infância. Petrópolis: Vozes, 2005.

HUIZINGA, Johan. Homo ludens: o jogo como elemento da cultura. 7 ed. São Paulo: Perspectiva, 2012.

KOHAN, Walter Omar. Infância: entre educação e filosofia. Belo Horizonte: Autêntica, 2003.

LARROSA, Jorge. Notas sobre a experiência e o saber de experiência. Revista Brasileira de Educação, n. 19, Jan./Fev./Mar./Abr. 2002. Disponível em:

http://www.scielo.br/pdf/rbedu/n19/n19a02.pdf

LUCKESI, Cipriano Carlos. O lúdico na prática educativa. Tecnologia Educacional. Rio de Janeiro. Vol. 22, pág. 119-120. Jul/Out, 1994.

MATURANA, Humberto; VERDEN-ZÕLLER, Gerda. Amar e Brincar: Fundamentos esquecidos do humano do patriarcado à democracia. São Paulo: Palas Athena, 2004.

PELLEGRIN, Ana de. O Espaço de Lazer na Cidade e a Administração Municipal. In:

MARCELlinO, Nelson Carvalho. (Org). Políticas Públicas Setoriais de Lazer: O papel das Prefeituras. Campinas-SP: Autores Associados, 1996. pgs. 31-38.

ROLNIK, Raquel. O que é a cidade. São Paulo: Brasiliense, 1994.

ROLNIK, Raquel. São Paulo. São Paulo: Publifolha, 2001.

ROLNIK, Raquel. O lazer humaniza o espaço urbano. In: SESC SP. (Org.). Lazer numa sociedade globalizada. São Paulo: SESC São Paulo/World Leisure, 2000.

ROLNIK, Suely. Cartografia sentimental: transformações contemporâneas do desejo. São Paulo: Liberdade, 1989.

SOLER, Reinaldo. Jogos cooperativos. Rio de Janeiro: Sprint, 2006. 
SPINK, Peter. O pesquisador conversador no cotidiano. Psicologia \& Sociedade. v. 20, Edição Especial, 2008. p.70-77. Disponível em: http://www.scielo.br/scielo.php?pid=S0102$71822008000400010 \&$ script $=$ sci_abstract $\&$ tlng $=\mathrm{pt}$

TAVARES, Regina Márcia Moura. Brinquedos e brincadeiras: patrimônio cultural da humanidade. Campinas: UNESCO, 2004.

\section{SOBRE OS AUTORES:}

\section{Bianca Rozenberg}

Mestre em Educação pela Universidade Federal de Viçosa (UFV); professora na Escola Vera Cruz (SP); membro do projeto Central dos Jogos (SP); participante do grupo de pesquisa Memória, Instituições e Subjetividade. E-mail: biancaroz@gmail.com

iD http://orcid.org/0000-0003-3304-6796

\section{Eduardo Simonini}

Doutor em Educação (UERJ/MG); professor no Departamento de Educação e no Programa de Pós-Graduação em Educação da Universidade Federal de Viçosa-Brasil; líder do grupo de pesquisa Memória, Instituições e Subjetividade. E-mail: simonini198@gmail.com

(iD https://orcid.org/0000-0002-3078-6994

\section{Denilson Santos de Azevedo}

Doutor em Educação (USP/SP); professor no Departamento de Educação e no Programa de Pós-Graduação em Educação da Universidade Federal de Viçosa-Brasil; membro do grupo de pesquisa Memória, Instituições e Subjetividade. E-mail: dazevedo@ufv.br

(iD) http://orcid.org/0000-0001-7938-3427

Recebido em: 29 de outubro de 2019 Aprovado em: 27 de novembro de 2019 Publicado em: 01 de janeiro de 2020 